\title{
Recuperación de la noción de ley natural frente al relativismo moral de occidente
}

\author{
José Manuel Martínez Guisasola \\ Centro de Estudios Teológicos de Sevilla \\ jomaguisasola@gmail.com \\ A D. José María Garrido Luceño, \\ buscador incansable de la verdad. \\ Se fue el profesor, ahora empieza su leyenda.
}

\begin{abstract}
Resumen: En el presente artículo se pretende hacer un acercamiento a la noción de ley natural con la intención de recuperarla como instancia objetiva que permita fundamentar el comportamiento ético en sociedades plurales como la de occidente, en la que conviven diversas mentalidades, distintos credos y un variado conjunto de sistemas axiológicos. Para ello se realiza un recorrido histórico que permita conocer tanto su génesis como su desarrollo para así entender las críticas que se han levantado contra ella. Terminamos exponiendo una nueva visión de ley natural que sea acorde con el carácter histórico del hombre.
\end{abstract}

\begin{abstract}
In this article we intend to approach our readers to the notion of natural law. We are trying to recover it as an objective instance allowing to base an ethical behavior in plural societies such as the western world, where different minds, different creeds and a huge set made of different axiological systems coexist. In order to reach our goal we have made an historical journey which allows us to know its origin as well as its development, helping our readers to understand the criticism which have been raised against it. The article ends up showing a new vision of this natural law according to the historical nature of man.
\end{abstract}

\section{BREVE RECORRIDO HISTÓRICO DEL CONCEPTO DE LEY NATURAL EN EL PRE-CRISTIANISMO}

El uso recurrente que el Magisterio de la Iglesia ha hecho y sigue haciendo de la ley natural para exponer ante la sociedad los postulados de la moral cristiana puede hacer pensar que dicho concepto tiene su origen en la reflexión 
teológica católica más genuina. Sin embargo, si nos adentramos en el estudio de la noción de"ley natural" podemos comprobar que no es en el seno de la Iglesia donde nace su conceptualización, si bien es verdad que se debe a los grandes teólogos católicos su desarrollo y formulación más álgida.

Como idea, la noción misma de ley natural ha estado presente en muchos pueblos y culturas, pues son muchas las sociedades que han tenido al menos la intuición de que existía una ley justa que estaba más allá de las leyes del propio Estado. Quienes mejor vislumbraron esta idea fueron los griegos. Pero los matices e interpretaciones de las distintas corrientes históricas de la Antigua Grecia son tan incisivos y conspicuos que se requiere una disección intelectual que facilite su comprensión. Algunos especialistas avezados en la temática que nos ocupa plantean una cuádruple clasificación de las corrientes de pensamiento que entre los helenos ha habido en relación a la existencia de un nomos que estuviera más allá de las leyes emanadas de la pluma de los gobernantes. ${ }^{1}$

La primera corriente de pensamiento es la etapa presocrática. En este período quien mejor expuso la idea de la existencia de una norma que estuviera más allá de las leyes del propio Estado fue el poeta trágico Sófocles (496 a.C. - 406 a. C.), que se basó en el mito de Antígona para exponer esta idea. En esta obra nos presenta al rey de Tebas Edipo, que se había casado, sin saberlo, con su propia madre, de nombre Yocasta. Tuvieron cuatro hijos, dos varones, Eteocles y Polinices y dos féminas, Ismene y Antígona quien da nombre a la obra. Edipo, tras conocer que su esposa es su progenitora se arranca los ojos y se dirige hacia el destierro. Ante la ausencia de un rey, serán sus dos hijos varones los que después de un mutuo acuerdo ocuparían el trono de Tebas durante un período de un año alternativamente. Fue Eteocles quien comenzó a gobernar a su pueblo, pero una vez transcurrido el año de su reinado se negó a ceder el poder a su hermano. Éste, encolerizado por ver como Eteocles se negaba a cumplir con lo pactado decide buscar ayuda en Argos, ciudad enemiga de Tebas, para ocupar el trono mediante las armas. Los dos ejércitos se enfrentaron en las puertas de la polis tebana resultando heridos de muerte ambos hermanos. La victoria final cayó del lado de los tebanos pero tras el deceso fratricida es Creonte, hermano de Yocasta y tío de Eteocles y Polinices, quien se alza con la corona para dirigir políticamente a su ciudad. Una de las primeras decisiones que toma el nuevo mandatario es prohibir que el cuerpo de este último sea enterrado según los ritos funerarios prescritos como castigo por haberse atrevido a guerrear contra su propia patria. De este modo imponía un castigo post-mortem a su sobrino dejando su cuerpo inerte a la intemperie para que fuese devorado por las alimañas. Algo cruel para la mentalidad de la época, pues para la cultura griega si un muerto no era enterrado su alma quedaba condenada a vagar por toda la eternidad sin

Cf. Rafael RAMIS, “Desarrollo histórico de la idea de ley natural (I): Antigüedad y Edad Media” en Francisco J. CONTRERAS, El sentido de la libertad. Historia y vigencia de la idea de ley natural, Stella Maris, Barcelona, 2014, 18-19. 
encontrar descanso. Por eso, Antígona decide desobedecer la orden decretada por el nuevo rey tomando la resolución de recuperar el cuerpo sin vida de su hermano y darle su debida sepultura. Para ello pide ayuda a su hermana Ismene pero ésta, por temor a las represalias que supone la desobediencia de una ley regia rehúsa la petición de ayuda de Antígona. Sin embargo, ésta, decidida a ejecutar su plan con o sin ayuda, aprovechando la distracción de los guardias, tomó el cuerpo exánime de Polinices y lo depositó en una tumba excavada en la roca. Creonte es informado de que su sobrino, en contradicción con lo decretado por él, ha recibido sepultura. La noticia le supo a acíbar a nuestro rey y por ello dio la orden de que desenterraran el cadáver para que volviera a ser expuesto a público escarnio. El rey presionó a los guardias para que descubrieran a los causantes del desacato a su ley. Tras unas breves pesquisas se descubre a la autora. El rey entra en cólera al conocer que ha sido su propia sobrina la que ha osado desobedecerlo. Sospechando que no pudo haber actuado sola mandó traer a Ismene por si ella había cooperado con Antígona en dar sepultura a Polinices. En un primer momento, Ismene, llevada por el remordimiento de haberse negado a sepultar a su hermano, se confiesa culpable de colaboración y, por tanto, de desobediencia, pero Antígona, viendo que su hermana estaba mintiendo con la intención de silenciar su conciencia, confesó que había actuado sola y que Ismene no había tenido ningún tipo de participación en el enterramiento de Polinices. Finalmente Ismene es puesta en libertad y se inicia un interrogatorio contra Antígona. Reproducimos aquí un fragmento del diálogo entre tío y sobrina:

Creonte: (A Antígona). Y tú, tú que inclinas al suelo tu rostro, ¿confirmas o desmientes haber hecho esto?

Antígona: Lo confirmo, sí; yo lo hice y no lo niego.

Creonte: (...). Dime brevemente, sin extenderte, ¿sabías que estaba decretado no hacer esto?

Antígona: Sí, lo sabía. ¿Cómo no iba a saberlo? Todo el mundo lo sabe.

Creonte:Y, así todo, ¿te atreviste a pasar por encima de la ley?

Antígona: Sí, porque no ha sido Zeus quien las ha proclamado, ni la justicia que habita con los dioses de regiones inferiores; ni él ni ella las han establecido entre los hombres. Yo no creo que tus decretos sean tan poderosos para que tú, mortal, puedas transgredir las leyes no escritas e inmutables de los dioses. Ellas no existen desde hoy ni desde ayer, sino desde siempre; nadie sabe cuándo han aparecido. Yo no debo por temor a la voluntad de un hombre arriesgarme a que los dioses me castiguen. ${ }^{2}$

Antígona se defiende sosteniendo que ella debe guiarse por una ley de rango superior a la decretada por Creonte, pero esto no le valdrá para salvar su vida ya que el monarca decide sentenciarla a muerte por su desacato. Hemón,

2 SÓFOCLES, Antígona, v. 449-460. 
hijo de Creonte y prometido de Antígona, intercede ante su padre por la vida de su amada, pero éste no se retracta de su decisión y continúa adelante con el castigo de su sobrina por su desobediencia legal. Ésta, mientras espera en una celda a ser ejecutada, decide poner fin a su existencia y termina ahorcándose y Hemón, al visitarla en la celda en la que estaba recluida, tras descubrir su cuerpo inerte, la imita clavándose una espada. El monarca es informado de lo ocurrido y acude a la gayola a recoger el cuerpo de su hijo que él mismo se encarga de transportar en sus brazos hacia su palacio. Pero al llegar a él, descubre que su esposa Eurídice también se había suicidado al conocer la noticia de la muerte de su propio hijo.

Hasta aquí la genial tragedia urdida por la agudeza intelectual de Sófocles. De ella se puede extraer una conclusión fundamental en relación con el tema que nos ocupa y es que la desobediencia a las leyes de los dioses trae consigo consecuencias nefastas. Efectivamente, en el pequeño fragmento del diálogo entre Creonte y Antígona que hemos reproducido más arriba se aprecia con nitidez cómo ésta reconoce la existencia de unas leyes que están más allá de las decretadas por los gobernantes, leyes que gozarían de las siguientes características: tener un origen divino, no estar escritas en ningún soporte físico, tener un carácter inmutable y en cierta manera, poseer un determinado principio de universalidad dado que los postulados de ellas emanados no obligarían sólo en una determinada polis sino en todas ellas.

Así pues, en este relato tenemos un ejemplo claro de la existencia de un derecho basado en la voluntad de los dioses, voluntad que podía ser conocida por medio de los oráculos. Se tenía la idea de que el derecho provenía de la diosa Thémis ya que ella representaba la encarnación del orden divino así como de las leyes y las costumbres. Tal es así que a los jueces en no pocas ocasiones se les denominaba con el término themistopoloi, es decir, los sirvientes de Thémis. Junto a ella, los griegos solían colocar a la diosa Díke, que según nos cuenta Hesíodo en su Teogonía era la hija de Zeus y Thémis, y que vendría a ser la personificación de la justicia en el mundo humano. ${ }^{3}$

En esta primera corriente de pensamiento tenemos que destacar también el importante esfuerzo de los filósofos presocráticos por desarrollar este lenguaje mítico exponiendo que era posible conocer la voluntad de los dioses por una vía distinta a la tradicional. Los poetas griegos habían ahondado en los oráculos como medio para indagar esa voluntad, pero los filósofos de este período, al reflexionar sobre la noción de Díke, postulaban que la voluntad de los dioses podía ser conocida por la razón. ${ }^{4}$ En este sentido destacamos la gran aportación realizada por Heráclito ya que él planteaba que si los dioses actuaban en el mundo,

Cf. RAMIS, “Desarrollo histórico de la idea de ley natural”, 19-20.

4 Esta es una cuestión importante para nuestro estudio pues como veremos en páginas posteriores cuando entremos de lleno a hablar de la ley natural, comentaremos cómo el orden moral ínsito en ella puede ser reconocido solo por el uso de la razón. 
dicha actuación podía ser conocida y al conocerse, se comprendía también sus voluntades. ${ }^{5}$ En el conocimiento de esa voluntad entra en juego el lógos.

La segunda corriente de pensamiento coincide con el nacimiento de la sofística. ${ }^{6}$ Si la etapa anterior estaba caracterizada por el pensamiento teológico propio de los poetas y el pensamiento racional de los filósofos presocráticos, en ésta lo más característico fue la circunscripción puramente política de la ley como resultado de su secularización. Lo que hicieron los sofistas fue eliminar la visión ontológica de la ley. Entre los presocráticos no encontramos la confrontación entre nómos y phýsis, pero en cambio los sofistas se plantean esta distinción, llegando a concluir que la ley no solo puede ser justa por sí misma o por su propia naturaleza, sino que también puede serlo por convención, es decir, hay cosas justas como resultado de un consenso entre los miembros que componen una polis. No es que la sofística negara la existencia de una ley natural, sino que no le daban valor para la configuración de la vida política. Ésta debía basarse solo en la nómo díkaion, es decir, en las cosas justas por la ley consensuada en oposición a la phýsei díkaion o las cosas justas por naturaleza. ${ }^{7}$

Pero este planteamiento sofístico empezaría a ser corregido por los pensadores de la tradición socrática, en concreto por Platón y Aristóteles, comenzando así la tercera corriente de pensamiento en relación a la temática que nos ocupa. Para el primero era una prioridad recuperar la ontología de la ley desdibujada por los sofistas. Para ello asume la noción de lógos presentada por Heráclito para hacer derivar de esa noción a la idea misma de justicia. Teniendo en cuenta la relación del lógos con la divinidad observamos que para Platón la ley no era más que una donación de ésta última a los hombres para que pudieran vivir en comunidad. En este sentido el nómos vendría a ser el orden divino comunicado a la pólis y no tanto el resultado de un consenso. Es decir, para Platón no puede haber pólis sin nómos y no puede haber nómos sin lógos, y dado que no hay lógos sin carácter divino, no puede haber pólis sin una ley que provenga de la divinidad. Con ello da contenido a la idea de justicia, que la concibe como la"vengadora de

5 “En el terreno de las ideas, con Heráclito comenzó asimismo un proceso de secularización de la justicia, puesto que la intervención de los dioses tenía un reflejo en el mundo y podía ser comprendida por los humanos. Heráclito, autor de numerosos aforismos que se han conservado parcialmente, dejaba de tener presente a Thémis como diosa de la ley, portadora del designio divino, y pasaba a ocuparse de Díke, en relación con otros conceptos, sobre todo con lógos, que era el 'decir' o la 'razón' en un sentido amplio. El lógos —según Heráclito- existía siempre, pero unos lo comprendían y otros no: unos estaban despiertos y otros dormidos, como se dice en el aforismo B1. Los que estaban despiertos buscaban la auténtica 'naturaleza de las cosas' (phýsis) y mostraban cómo era. La verdadera naturaleza estaba, existía, pero no todos la podían ver. Esta comprensión, la esencia de la actividad filosófica, fue designada por Heráclito con el término phronein, que significa comprender": RAMIS, "Desarrollo histórico de la idea de ley natural", 20-21.

6 Para profundizar sobre la sofística como sistema de pensamiento cf. Johannes HIRSCHBERGER, Historia de la filosofía I, Herder, Barcelona, 1994 ${ }^{15}$, 71-75; cf. Johann FISCHL, Manual de historia de la filosofía, Herder, Barcelona, 19947, 54-60.

7 Cf. RAMIS, “Desarrollo histórico de la idea de ley natural”, 25. 
los que faltan a la ley divina". ${ }^{8}$ El hombre que quiera ser feliz debe seguirse por esa theíou nómou pues de lo contrario, es decir, en el caso en que el hombre se obstine en dirigir su vida de espaldas o en desobediencia a ella, experimentará el abandono de la divinidad.

Con esto lo que Platón pretende es corregir todo el planteamiento de los sofistas, ya que éstos no habían entendido el concepto de phýsis en toda su amplitud, sino que lo habían circunscrito sólo al ámbito biológico, sin ninguna referencia al lógos tal y como ya lo plantearon tanto Heráclito como Parménides.

A este respecto quisiéramos traer a colación las palabras del profesor Rafael Ramis que sobre la temática que nos ocupa se pronuncia afirmando que:

"Para Platón, por lo tanto, no debía de prevalecer una phýsis basada en la tensión y en la fuerza de unos sobre otros para dominar la pólis, sino unas nómoi basadas en el lógos, en el que la norma se adecuase a su naturaleza (phýsis) misma. Eso sólo podía hacerse a través del conocimiento de las ideas (eídos), que hacía que cada cosa fuera más parecida a su esencia. Así, las nómoi tenían que basarse en las del mundo de las ideas, que debía ser el foco de referencia para cualquier realización práctica de esa idea. Al mundo de las ideas se accedía a través de la contemplación. En el caso de la ley, a través de la contemplación de la ley divina (theios nómos), de la que emanaba la justicia. Platón desconfiaba de las leyes escritas: quería que fueran los filósofos los que, buscando la adecuación de cada cosa a su naturaleza, hallasen unas normas que fuesen la emanación de la justicia para la pólis. Para Platón esta ley divina no tenía fundamento en la phýsis, sino en el mundo de las ideas, y estaba en plena consonancia con la certeza (episteme) y la virtud (aretê)" ${ }^{\prime}$.

Así, pues, para el fundador de la Academia existía una gran diferencia entre las leyes escritas y aquellas otras leyes a las que se podía acceder a través de la contemplación del mundo de las ideas. Diferenciación que remite a esa bipolaridad de la que ya hemos hablado entre el nómo díkaion y el phýsei díkaion. Las primeras están escritas como resultado de un consenso entre los gobernantes y son válidas en tanto que consensuadas, aunque solo temporalmente y para una determinada pólis. Las segundas, en cambio, no están escritas en papel ya que se encuentran en el mundo de las ideas, y serían válidas no como resultado del consenso sino per se, en orden a su misma naturaleza divina, y que en base a esa naturaleza divina gozan de eternidad, es decir, no son temporales y obligarían a todos los seres humanos y no solo a los de una determinada pólis.

\footnotetext{
8 "... el dios (théos) que tiene en sus manos el principio, el fin y el medio de todas las cosas, dando vueltas conforme a su naturaleza (katà phýsin), cumple derechamente su camino. Síguele constantemente la justicia (díke), vengadora de los que faltan a la ley divina (theíou nómou); atenido a ella le sigue también, modesto y templado, el hombre destinado a la felicidad; en cambio, aquel otro que, exaltado por su arrogancia (...), inflama su alma de insolencia, como si no tuviese necesidad de gobernante ni de guía alguno, sino que él mismo fuera capaz de dirigir a otros, es abandonado en soledad por el dios...": PLATÓN, Las Leyes, 715e-716b.

9 RAMIS, “Desarrollo histórico de la idea de ley natural”, 27-28.
} 
Aristóteles se sitúa en la misma línea que su maestro pero hay diferencias notables entre uno y otro. Una de estas discrepancias radica en la visión que de la phýsis tienen uno y otro. Platón tenía una concepción peyorativa e imperfecta de ella, ya que la perfección solo se encontraba en el mundo de las ideas, por eso el ideal del gobernante no era el político sino el filósofo, que por medio de la contemplación intentaba que este mundo se asemejara a su original. En cambio, Aristóteles no comparte esta percepción negativa de la naturaleza que tenía su mentor. Él fue un gran observador de la misma, observación que lo estimuló a realizar numerosos estudios empíricos, poniendo las bases de disciplinas científicas, como la biología o la física, entre otras.

Para el de Estagira la phýsis tenía un doble significado, uno físico y otro metafísico. De este modo podemos acercarnos al mundo que nos rodea y descubrir las leyes que lo rigen (leyes biológicas, leyes matemáticas, leyes físicas...) pero también podemos descubrir otras leyes que tienen que ver con la naturaleza misma de las cosas. Esto llevó a Aristóteles a hacer una distinción entre la ley particular y la ley común. La primera era la que cada pueblo se daba para sí, interviniendo para ello el consenso político, mientras que la segunda era la ley conforme a la naturaleza misma de las cosas. Es decir, Aristóteles acepta la existencia de una noción de justicia según la naturaleza que estaría más allá de lo meramente consensuado. ${ }^{10}$

La cuarta corriente de pensamiento que merece ser resaltada coincide con la época helenística correspondiendo históricamente con la muerte de Alejandro Magno. La característica más significativa de este período fue la visión cosmopolita, que se produjo como resultado de la concepción imperialista tras las conquistas bélicas que también trajo consigo la expansión del idioma griego. Esto vino acompañado de una desconfianza en las polis debido a la inestabilidad política que en ellas se había generado, de modo que ya el individuo no se circunscribía a una determinada ciudad, sino que se sentía ciudadano del mundo.

La escuela estoica contribuyó notablemente en la expansión de esta mentalidad ya que para esta corriente filosófica el hombre era un habitante del kósmos. Siendo esto así, para los pensadores de esta escuela el ser humano tendría que adecuar su comportamiento a una ley universal, es decir, a una norma que fuera común a todos los miembros de nuestra especie. Esta ley universal tiene que estar regida por un lógos divino perfectamente comprensible por la razón

10 “Diviso la ley (nómon) en particular (idion) y en común (koinón): particular, la establecida para cada pueblo respecto de él mismo, y ésta es en parte no escrita, y en parte escrita. Común es la ley conforme a la naturaleza (katá phýsin). Pues de acuerdo con esto existe algo comúnmente justo e injusto de acuerdo con la naturaleza (phýsei), lo cual todos adivinan, aunque no exista ningún acuerdo común entre unos y otros pueblos, ni pacto alguno; así como se nos presenta Antígona en Sófocles cuando dice que es justo sepultar a Polinices, cuya inhumación estaba prohibida, como quiera que esto es justo por naturaleza (os phýsei òn touto díkaion)": ARISTÓTELES, Retórica, I 13 1373b, 4-12. 
humana y que fuera garantía del orden del mundo. En este sentido todas las leyes que pretenden orientar el comportamiento humano, tanto las morales como las jurídicas, deben coincidir con este lógos. Como se puede apreciar, se produce una recuperación de las ideas presocráticas, y en concreto, del pensamiento de Heráclito. Efectivamente, con el estoicismo se pusieron las bases para que durante todo el período helenístico no se pusiera tanto énfasis en las leyes consensuadas por los distintos Estados como en ahondar en el conocimiento de una ley universal vinculada a la naturaleza de las cosas y cuyo conocimiento era perfectamente alcanzable por la razón humana.

El estoicismo, como escuela filosófica, tuvo un gran desarrollo y una enorme difusión por toda la cuenca del Mediterráneo, por eso no debe extrañarnos que sus ideas penetraran con tanta avidez en la cultura latina, hasta el punto de convertirse en el caldo de cultivo para fraguar el nacimiento del pensamiento jurídico romano. Éste había asumido de aquél su idea de universalismo y la existencia de una norma de carácter universal que tuviera validez para todos los pueblos. Obviamente esta concepción estoica encajaba a la perfección con la situación socio-política de Roma que se encontraba en un proceso de expansión territorial.

A este respecto es pertinente traer a colación la labor intelectual de Marco Tulio Cicerón, quien se esforzó por traducir todas las categorías filosóficas y jurídicas propias del helenismo a la mentalidad latina. Para el orador romano existe una ley verdadera que coincide con la razón y que a su vez es conforme a la naturaleza. Esta ley no se circunscribe a un determinado territorio sino que goza de un carácter universal, es decir, es válida para todos los pueblos y culturas y no puede ser dispensada por autoridad política alguna. Su validez trasciende la historia, por lo que debe considerársela como inmutable y eterna. ${ }^{11}$ Como puede observarse, la influencia del estoicismo en Cicerón es innegable.

\section{NOCIÓN DE LEY NATURAL PARA LA TEOLOGÍA CRISTIANA}

Ya hemos comentado que la noción de ley natural no nace dentro del cristianismo, pero sí es cierto que éste lo asumió prácticamente desde sus orígenes. Basta con echar una mirada a la carta de San Pablo a los Romanos para percatarse como el Apóstol alude a ella para poner en comparación el comportamiento de los judíos que debe regirse por la ley mosaica, en concreto por los

11 "Existe una ley verdadera (vera lex) y es la recta razón (recta ratio), conforme con la naturaleza (naturae congruens), común para todos, inmutable, eterna, que impulsa al cumplimiento del deber con sus mandatos (...). Esta ley no puede sustituirse con otra. Ni el Senado ni el pueblo pueden eximirnos de ella (...). No habrá una ley en Roma otra, en Atenas; una hoy; otra mañana; sino que una ley única, eterna e inmutable regirá todas las naciones y en todos los pueblos": Marco Tulio CICECÓN, República, III, 33. 
diez mandamientos, y el comportamiento de los gentiles, que poseen también otra ley de contenido similar y cuya observancia es necesaria para la salvación. Escuchémoslo directamente a él:

\begin{abstract}
"Cuantos pecaron sin conocer la ley, morirán también sin ley; y cuantos pecaron estando sujetos a la ley, por la ley serán juzgados.Y es que Dios no considera justos a los que oyen la ley, sino a los que la cumplen: éstos serán justificados. En efecto, cuando los gentiles, aunque no tienen ley, cumplen naturalmente las prescripciones de la ley, para sí mismos son ley. Ponen de manifiesto que la realidad de esa ley está escrita en su corazón; así lo atestiguan además su conciencia y los juicios contrapuestos que emiten de condenación o alabanza... para el día en que Dios juzgue las acciones de los hombres, según mi Evangelio, por Cristo Jesús." $(\mathrm{Rm} 2,12-16){ }^{12}$
\end{abstract}

Efectivamente, para Pablo los paganos poseían un sentido del bien y del mal fundamentado en el conocimiento de una ley, no revelada por Dios al modo en que el pueblo hebreo poseía el decálogo, pero sí accesible por la razón humana. Esta idea paulina y las ideas normativas emanadas del pensamiento estoico y platónico influyeron en gran medida en la configuración del desarrollo teológico de los primeros siglos del cristianismo. Grosso modo podría decirse que la reflexión teológica patrística partía de la existencia de una ley natural de origen divino que tenía su resonancia en la mente y en el corazón de los hombres.

De entre todos los autores de la patrística quien mejor disertó sobre la temática que nos ocupa fue San Agustín. El obispo de Hipona distinguía entre el derecho natural y el derecho positivo, subrayando la primacía de aquél sobre éste. Distinción ésta no exclusiva de él ya que otros autores de este período habían dividido el derecho en estas dos dimensiones. ${ }^{13}$ Pero lo que resulta más llamativo del pensamiento del prelado africano fue que pusiera las bases para que en el desarrollo teológico posterior se pudiera llegar a la división tripartita del derecho, distinguiendo entre la ley eterna, la ley natural y la ley positiva. Nos parece fundamental la idea de lex aeterna que él define como "la razón y voluntad divina que manda observar y prohíbe alterar el orden natural".$^{14}$

Tres elementos son destacables en esta lacónica definición que el de Hipona nos ofrece. La primera es el origen divino de esta ley, es decir, no es el hombre quien la promulga sino que es la razón y la voluntad divina quien lo hace. El hombre la recibe, pero no la inventa. La segunda consideración es la profunda carga moral que esta ley conlleva pues posee la fuerza para ordenar determinadas acciones así como para prohibir otras. Y finalmente, se resalta la existencia de un orden natural, orden que tiene que ver con la moralidad, puesto

12 El texto citado está tomado de la Biblia de Jerusalén.

13 San Ambrosio de Milán fue otro de los teólogos que distinguieron entre el derecho natural y el derecho positivo dándole mayor importancia al primero que al segundo.

14 San AGUSTÍN, Contra Faustum 22, 27. 
que es obligado respetarlo ya que su alteración voluntaria haría al sujeto racional incurrir en pecado. ${ }^{15}$

Si el de Tagaste puso las bases de esta división tripartita a la que hemos aludido más arriba, quien mejor la desarrolló fue Santo Tomás de Aquino. Por eso vamos ahora a centrar nuestra atención en la propuesta teológica del Doctor Angélico. Nos vamos a acercar primero a la noción misma de ley y posteriormente a su clasificación en eterna y natural.

\subsection{Noción de ley en Santo Tomás de Aquino}

Antes de entrar de lleno en el estudio de la ley natural, es conveniente desde el punto de vista metodológico, detenernos primero en la noción misma de ley. El Aquinate la define como "prescripción de la razón, en orden al bien común, promulgada por aquel que tiene el cuidado de la comunidad". ${ }^{16}$

La definición nos parece más que sugerente, ya que en ella se nos aporta cuatro elementos importantes para captar su esencia misma. El primero de estos elementos es la"razón". Es decir, para Santo Tomás de Aquino la ley tiene que emanar de la razón práctica, o lo que es lo mismo, ésta debe ser considerada como la causa eficiente de aquélla. Aquí se puede apreciar toda la influencia de la filosofía griega que ya hemos descrito en las páginas precedentes, donde la existencia de un lógos era garantía de la naturaleza de una ley universal.

Para nuestro dominico, la ley tiene su origen en la razón y no tanto en la voluntad, aunque reconoce una cierta participación de ésta pero sin llegar a ser nunca causa eficiente. Entre los escolásticos, existía la convicción de que ambas potencias intervenían en la formación de una ley, pero Santo Tomás da la primacía a la primera sobre la segunda. Esto nos parece de suma importancia porque con ello lo que se afirma es que la ley no puede ser el resultado del capricho del legislador, sino que tiene que emanar de su raciocinio, es decir, la ley ha de tener una razón de ser. La voluntad del legislador por sí sola es insuficiente para conformar una norma con capacidad de obligar. Por eso podríamos afirmar que cualquier conjunto normativo que sea irracional no obliga en absoluto. ${ }^{17}$

15 No es nuestra intención ahondar ahora en la noción de pecado, pero nos resulta pertinente la idea del mismo que manejaba San Agustín ya que éste se entendía como una transgresión del orden fijado por la ley eterna. "Peccatum est factum vel dictum vel concupitum aliquid contra legem aeternam": Ib., 22, 27. Es decir el pecado es un dicho o un hecho o un deseo contra la ley eterna.

16 Santo TOMÁS de AQUINO, Summa Theologiae, I-II, q. 90, a.4.

17 El teólogo español Royo Marín, gran conocedor del pensamiento de Santo Tomás de Aquino, refiriéndose a esta cuestión escribe: "La ley es esencialmente un acto de la razón práctica, y no de la voluntad. Porque es propio de la razón, y no de la voluntad, ordenar al hombre al debido fin por los medios más aptos y proporcionados. Ciertamente que en la formación de la ley interviene también la voluntad, pero no es ella causa eficiente de la misma, ya que entonces el simple capricho del legislador podría erigirse en ley. Una ley irrazonable deja ipso facto de ser ley, o, mejor, no puede jamás erigirse en ley": Antonio ROYO MARÍN, Teología Moral para seglares, Moral fundamental y especial I, BAC, Madrid, 20077, 108. 
El segundo elemento de la definición del Aquinate tiene que ver con el "bien común". Efectivamente, toda ley emanada de la razón del legislador debe estar orientada a un fin específico, ese fin no es otro que el bien común. En este sentido se puede afirmar que si la razón se constituye en causa eficiente de la ley, el bien común es su causa final. Esto significa que si una ley se promulgara con la intención de beneficiar a un solo individuo, o a un grupito concreto de personas en detrimento de la mayoría, dicha ley carecería de carácter de ley. Y la carencia de este carácter normativo se ahondaría aún más si además de ir en beneficio de una minoría la ley preceptuara una acción mala o perniciosa para el conjunto de la sociedad, es decir, en menoscabo de todos los ciudadanos.

El tercer elemento aportado en la definición que estamos comentando tiene que ver con la promulgación, que es condición indispensable para que la ley tenga carácter de obligatoriedad.Y el último de estos elementos hace referencia al sujeto o sujetos que tienen el cuidado de velar por la comunidad. Es decir, no todos los miembros de una sociedad tienen el poder de legislar. Esta facultad recae en una persona o en un grupo de ellas. ${ }^{18}$

Esta definición nos será de gran utilidad para poder ahora entender la clasificación a la que antes hemos aludido.

\subsection{La ley eterna}

El Aquinate, una vez que define la noción misma de ley, no entra inmediatamente a analizar la ley natural sino que previamente se detiene a analizar la noción de ley eterna ya que ésta es previa a aquélla.Y al detenerse en su estudio la define como "la razón de la divina sabiduría en cuanto dirige todos los actos y movimientos".${ }^{19}$ Es decir, todo cuanto existe ha surgido de la sabiduría divina. Significa que Dios, antes de crear concibe en su mente cómo será la creación y una vez que la ha concebido, posteriormente la materializa.

18 Estos elementos que hemos comentado son interesantes para tenerlo en cuenta sobre todo en el contexto sociopolítico en el que nos encontramos. En la inmensa mayoría de los países occidentales la forma de gobierno es la democracia en la que existe la división de poderes: el poder ejecutivo, el poder legislativo y el poder judicial. Al primero le corresponde la gestión del Estado ejecutando políticas conforme a las leyes. Al segundo le corresponde aprobar o derogar dichas leyes mientras que al tercero le compete hacer respetar las leyes vigentes así como su interpretación. En el caso de España, las Cortes Generales están compuestas por dos cámaras: el Congreso de los Diputados, conocido también como Cámara Baja, y el Senado o Cámara Alta. Estos dos órganos son la sede del poder legislativo. Esto significa que tanto los diputados como los senadores son los encargados de promulgar nuestras leyes. Pues bien, si echamos un vistazo a nuestro panorama jurídico podemos observar con asombro y, no sin una cierta congoja, como nuestros legisladores se han olvidado por completo de recurrir a la razón para promulgar nuestras leyes. No es ninguna novedad afirmar que los políticos que nos representan se mueven más por intereses particulares que por el bien del conjunto de la sociedad. De este modo, tanto la causa eficiente como la causa final de una ley brillan por su ausencia.

19 "Lex aeterna nihil aliud est quam ratio divinae sapientiae, secundum quod est directiva ómnium actuum et motionum": Santo TOMÁS de AQUINO, Summa Theologiae, I-II, q.93, 1. 
Sería, de modo análogo, parecido a un artista. Pensemos en un pintor. Éste, antes de dibujar, concibe primero en su mente la obra que quiere pintar y cuando ya la ha visualizado en su intelecto se lanza a plasmarla en el lienzo. De este modo tenemos que en la mente de Dios es donde se encuentra la causa ejemplar de todo lo creado. De aquí se deriva su adjetivación como eterna. Si esta ley ha sido concebida por la mente divina, la aplicación del epíteto es teológicamente correcta ya que lo que Dios concibe en su intelecto no puede tener ni principio ni final, puesto que correspondería a una operación ad intra. Son las operaciones ad extra, tales como la creación del mundo o la redención de la humanidad, las que Dios realiza dentro del tiempo.

Su conceptualización como eterna ha llevado a algunos pensadores a negar su carácter de ley, pues una de las características que ésta debe poseer es que vaya dirigida a alguien. $\mathrm{O}$ dicho con otras palabras, una ley no puede gozar de carácter de ley si no tiene súbditos que tengan que estar sometidos a ella. Tal y como hemos visto en la definición que el propio Santo Tomás ha hecho de la ley, ésta tiene que ser promulgada pero, si la ley eterna ha sido concebida en la mente de Dios antes de la creación de la humanidad, ¿quién estaba sometida a ella?

Esta objeción planteada desde una perspectiva jurídica ha sido ampliamente contestada por varios teólogos siguiendo la misma línea argumentativa del Aquinate. De entre ellos optamos por la respuesta de Royo Marín que ante la objeción planteada responde en los siguientes términos:

"No vale objetar que, donde no hay súbditos eternos, no puede haber ley eterna. Porque esos súbditos existían en la mente divina desde toda la eternidad. Para Dios no hay pasado ni futuro, sino un presente siempre actual. Dios tenía presentes a todas sus futuras criaturas en su mente divina y desde toda la eternidad determinó por la ley eterna las obligaciones a que tendrían que someterse. La promulgación activa (que es la promulgación propiamente tal, como acto del legislador) se verificó eternamente en la mente divina; la pasiva (o mera divulgación entre los súbditos) no se realizó sino cuando aparecieron de hecho las criaturas." ${ }^{20}$

Como se ha podido observar, la distinción entre promulgación activa y pasiva ha sido la clave explicativa para la objeción arriba expuesta. Ciertamente, Dios antes de crear concibe en su mente cómo debe funcionar todo el mundo material. Por eso antes de que el universo aparezca de la nada, el Creador visualiza en su mente todas las leyes físicas, matemáticas y biológicas que deben regirlo. Del mismo modo, antes de crear a los hombres, Dios concibe en su mente un orden moral que éstos deben respetar por libre elección sometiéndose voluntariamente a la ley eterna.

Este orden moral salvaguardado por esta ley proviene del intelecto divino, es decir, la razón es su causa eficiente, no proviene de la voluntad aunque ésta

20 ROYO MARÍN, Teología Moral para seglares, 127-128. 
intervenga en su plasmación. De este modo el orden moral emanado de esta ley no responde al capricho del legislador. Este fue el error que cometió Guillermo de Ockham y los nominalistas, considerar que el bien y el mal no dependen de la naturaleza de las cosas sino de la voluntad divina. Fue a partir del nominalismo cuando se fue fraguando la corriente del positivismo jurídico divino que venía a postular que no existe un bien y un mal objetivo basado en la esencia de las cosas, sino que lo que está bien o mal es porque Dios, a través de su voluntad, ha decidido qué acciones entran en una categoría y cuáles en otra.

Este error tiene graves consecuencias ya que si se aceptara la postura nominalista habría que concluir que no existen acciones intrínsecamente malas desde el punto de vista moral, sino que malo sería aquello que el Creador decidió que fuera malo pudiendo haber establecido lo contrario. Es decir, si el adulterio o la mentira son acciones pecaminosas es porque Dios así lo dispuso, pero no porque en sí misma dichas acciones merezcan ser catalogadas como malas. ${ }^{21}$

El yerro nominalista se debió a una mala comprensión de la noción misma de ley eterna así como a una incapacidad para distinguir correctamente entre existencia y esencia. Efectivamente, la existencia de las cosas depende de la voluntad divina que quiso libremente crearlas, pero su esencia no depende de la voluntad sino del intelecto divino. Esto implica que desde el punto de vista moral las cosas no son como Dios quiere que sean sino que son tal y como Él las ha concebido en su mente. Si la mentira es un mal moral no es porque Dios así lo quiere sino porque su entendimiento lo concibe como un mal. ${ }^{22}$

Pues bien, una vez que hemos abordado la noción misma de ley eterna vamos ahora a presentar las propiedades de dicha ley.

La primera de ellas es la cognoscibilidad. La ley eterna, al estar en la mente de Dios, es inmutable en sí misma ya que en la mente divina no hay posibilidad de error. Pero que su lugar de residencia sea el intelecto divino no implica que el ser humano no tenga acceso a ella. Como bien expone el Doctor Angélico, hay dos formas de conocer una cosa, bien conociéndola en sí misma o bien a través de sus efectos. En sí misma no podemos conocerla, solo las personas que tengan

21 Cf. José Manuel MARTÍNEZ GUISASOLA, “La perspectiva cristológica en la renovación de la Teología Moral", Isidorianum 51-52 (2017) 110-111.

22 "Ni siquiera la voluntad de Dios podría alterar el orden esencial de la moralidad que se funda y apoya en la naturaleza misma de las cosas.Y ello porque, como explica Santo Tomás, la existencia de las cosas se debe a la voluntad divina, que quiso libremente crearlas; pero la naturaleza o esencia de las cosas no depende de la voluntad divina, sino remotamente de la esencia misma de Dios y próximamente del entendimiento divino. El arquetipo de todas las cosas está en el entendimiento divino, no en la divina voluntad; y por eso a cada una de las cosas le da Dios el ser que le conviene según su propia e intrínseca naturaleza, tal como la concibe el entendimiento divino, o sea tal como debe ser.Y así, v.gr., Dios no podría legislar que dos y dos sean cinco, o que la blasfemia sea lícita, etc, etc., porque no lo sufre la naturaleza misma de las cosas tal como las ve el entendimiento divino. Queda, pues, sentado que existe un orden moral objetivo fundado en la naturaleza misma de las cosas e independiente de toda voluntad humana e incluso divina en el sentido que acabamos de explicar": ROYO MARÍN, Teología moral para seglares, 84 . 
la visión beatífica la conocen de este modo. Pero el homo viator puede captarla por irradiación, de este modo nuestro conocimiento de la ley eterna sería mudable ya que dicha irradiación puede ser mayor o menor en cada persona y en cada cultura. Es decir, no todos los hombres ni todos los pueblos conocen esta ley con la misma intensidad, sino que dependerá de las circunstancias que condicionen la recepción de sus irradiaciones. ${ }^{23}$

La segunda de sus propiedades es la primacía. Con ello se quiere dar a entender que la ley eterna es la fuente de todas las demás leyes. O dicho con otras palabras, que todas las leyes deben derivar de ella, tanto como causa ejemplar, ya que la ley eterna es el modelo de todas las demás, y también como causa eficiente, puesto que la potestad de una norma para imponer obligaciones proviene de la ley eterna. Por consiguiente, todo conjunto normativo que la contradiga carece de carácter de ley. ${ }^{24}$

La tercera de sus propiedades es la extensión. Significa que todas las cosas existentes están sometidas a esta ley, tanto los seres irracionales como los racionales. Sin embargo, el modo de sometimiento es distinto en unos y otros. Los primeros se encuentran sujetos a ella instintivamente, es decir, se tratan de seres determinados por la misma naturaleza a actuar de acuerdo a los postulados de la ley eterna. En cambio, los segundos, al poseer razón, deben someterse a ella mediante el conocimiento y la voluntad. Los seres racionales no están ni determinados ni "obligados" a seguir los postulados de esta ley ya que al tratarse de sujetos con voluntad tienen la facultad de decidir aceptarlos o rechazarlos.

Pero, ¿no se podría afirmar entonces, que si un ser racional rechazara voluntariamente someterse a los principios de la ley eterna éste dejaría, por tanto, de estar sujeto a ella? Como primera impresión, podría decirse que sí, pero analizando la cuestión más a fondo se puede ver que no es así ya que de lo contrario no se cumpliría esta tercera propiedad. Para dilucidar esta cuestión tenemos que distinguir dos tipos de preceptos en la ley eterna con respecto a los seres racionales. Uno de estos preceptos son los directivos, que serían aquellos principios que dirigen al homo viator hacia su fin último que es Dios mismo. La asunción de tales principios debe realizarse por medio del conocimiento y de la voluntad, es decir, el hombre a través de la razón conoce lo que esa ley establece y por medio de la voluntad, en el ejercicio de su libertad, decide seguirlos. Pero si haciendo uso de esa misma libertad decidiera no someterse a los principios directivos incurriendo con ello en un pecado, entonces entran en escena los principios vindicativos, que se encuentran presentes en la ley eterna y que establecen la aplicación de una pena proporcional al sujeto que voluntariamente haya decidido desobedecer lo establecido en los principios directivos, una pena que será satisfecha en esta vida o en la otra.

23 Cf. Santo TOMÁS de AQUINO, Summa Theologiae, I-II, q.93, 2.

24 Cf. Ib., I-II, q. 93, 3. 
En este sentido, todo ser que posea voluntad se encuentra inexorablemente sometido a la ley eterna. Nuestra voluntad solo es libre ante los preceptos directivos, pero no somos libres para evadirnos de los vindicativos. Ni siquiera Dios, autor de esta ley, puede dispensar a un sujeto de la aplicación de estos últimos principios.

\subsection{La ley natural}

Con todo lo que hemos expuesto anteriormente nos encontramos en mejor situación para comprender el concepto de ley natural, ya que Santo Tomás de Aquino la define como "la participación de la ley eterna en la criatura racional" ${ }^{25}$ Efectivamente, el orden moral concebido por la mente de Dios antes de la creación puede ser conocido por el hombre a través de la razón natural. Este es uno de los motivos por los que esta ley recibe tal nomenclatura. El segundo de tales motivos es porque sus preceptos se deducen racionalmente de la misma naturaleza humana, por eso todo hombre está obligado a su cumplimiento.

No obstante, si bien es cierto que sus preceptos se deducen racionalmente, éstos no siempre resultan fácilmente aprehensibles. Esta gradualidad en su aprehensión intelectiva nos lleva a afirmar que en la ley natural se dan tres categorías distintas de preceptos.

En una primera categoría tendríamos los preceptos primarios que estarían presentes en la mente de cada hombre, por lo que no cabe argumentar ignorancia sobre su existencia. Este primer precepto tiene una formulación simple pero esencial "bonum est faciendum et prosequendum, et malum vitandum". ${ }^{26}$ Pero aparte de éstos, tenemos también en la ley natural los preceptos secundarios que se pueden clasificar a su vez en otras dos categorías: las conclusiones próximas y las remotas. Las primeras son aquellas que fluyen directamente de los primeros principios y para cuya deducción no se requiere un gran esfuerzo de la razón por lo que son accesibles a todo hombre. Aquí habría que colocar los preceptos del decálogo cuyo contenido moral no se circunscribe solo al pueblo que los re-

25 Ib., I-II, q.91, 2.

26 La argumentación del Doctor Angélico sobre esta cuestión es la siguiente:“Entre las cosas que son objeto del conocimiento humano se da un cierto orden. En efecto, lo que primariamente cae bajo nuestra consideración es el ente, cuya percepción va incluida en todo lo que el hombre aprehende. Por eso, el primer principio indemostrable es el siguiente: 'No se puede afirmar y negar a la vez una misma cosa'; principio que está basado en las nociones de ser y no ser, y en el cual se fundan todos los demás principios, como dice el Filósofo. Pues bien, como el ser es lo primero que cae bajo toda consideración, así el bien es lo primero que aprehende la razón práctica, ordenada a la operación, puesto que todo agente obra por un fin, el cual tiene naturaleza de bien. Por tanto, el primer principio de la razón práctica será el que se funda en la naturaleza del bien: 'Bien es lo que todos los seres apetecen'. Este, pues, será el primer precepto de la ley: Se debe obrar y proseguir el bien y evitar el mal. Todos los demás preceptos de la ley natural se fundan en éste, de suerte que todas las cosas que deban hacerse o evitarse, en tanto tendrán carácter de preceptos de ley natural en cuanto la razón práctica los juzgue naturalmente como bienes humanos": Ib., I-II, q. 94, 2. 
cibió por revelación divina. A este respecto conviene recordar la experiencia del apóstol Pablo que reconoce la existencia de un orden moral en la cultura griega coincidente con el recogido en los mandamientos dados por Yahvé al pueblo hebreo. Si éste obtuvo este conocimiento moral por revelación, aquél lo consiguió por la razón. Así, pues, con respecto al contenido ético de las conclusiones próximas no cabe una ignorancia de por vida pues como hemos expuesto, su contenido puede ser captado sin grandes esfuerzos por parte del intelecto. Lo que sí podría darse es una ignorancia inculpable transitoria, es decir, el hecho de que una persona, sin culpa alguna por su parte, desconociera solo temporalmente las obligaciones morales emanadas de tales principios. ${ }^{27}$ Por el contrario, las conclusiones remotas de la ley natural son aquellas a las que se llega con un raciocinio mucho más arduo y difícil ya que la obligación moral de sus postulados no son tan evidentes a la razón como con las anteriores. Precisamente por esto, si en las conclusiones próximas se permitía una ignorancia inculpable transitoria también en las remotas la existencia de dicha ignorancia se da, admitiendo una temporalidad aún mayor con respecto a su desconocimiento, sobre todo si se trata de personas poco instruidas y formadas.

Si en las conclusiones próximas poníamos como ejemplo de contenido ético el decálogo, en las remotas podemos incluir principios como la ilicitud de la venganza privada o la indisolubilidad del matrimonio. Como se puede apreciar, captar la moralidad de estos dos últimos ejemplos requiere un esfuerzo racional mayor si lo comparamos con la aprehensión de otros principios morales como "no matar"o"no robar".

Pero aparte de las categorías, encontramos también en la ley natural un conjunto de propiedades al estilo de la ley eterna.

La primera de ellas es la unidad. Como bien sostiene Santo Tomás de Aquino, la ley natural contiene muchos preceptos, pero no constituye sino una sola ley y esto por un doble razonamiento. En primer lugar porque todos los preceptos de una ley dependen del primer principio que es quien garantiza la unidad ya que radican en él. Y en segundo lugar porque todos los preceptos contenidos en esta ley se ordenan a un único fin, el fin último que es la bienaventuranza eterna. ${ }^{28}$

Como segunda propiedad tenemos la universalidad. Esta propiedad se puede entender desde una doble perspectiva: universalidad en cuanto a la verdad y validez, y universalidad en cuanto al conocimiento.

En relación a su verdad, la ley natural es universal en cuanto que es la misma para todos los hombres, con independencia de la cultura a la que cada uno pertenezca o de la época histórica que le haya tocado vivir, ya que el fundamento de su validez reside en la misma naturaleza humana que es siempre la misma.

27 Cf. ROYO MARÍN, Teología moral para seglares, 131.

28 Cf. Santo TOMÁS de AQUINO, Summa Theologiae, I-II, q.94, 2. 
En este sentido se puede afirmar que la universalidad es totalmente absoluta por tratarse de los primeros principios.

Con respecto a los preceptos secundarios cabría decir que éstos gozan, de un modo general, de una validez universal por el mero hecho de derivar directamente de los primeros principios, sin embargo, en determinados casos, a tenor de las circunstancias cambiantes en que se puedan aplicar, se da la posibilidad de que no sean absolutamente universales en relación a su veracidad. Lo mismo cabría decirse de las conclusiones remotas, ya que cuanto más nos distanciemos de los primeros principios para ir aterrizando en lo particular se incrementa el riesgo de que el conjunto normativo de la ley natural vaya perdiendo su universalidad.

La misma argumentación cabría aplicar a la universalidad del conocimiento. El contenido moral de esta ley puede ser conocido universalmente por la razón humana, por lo que todos los hombres de todas las épocas históricas y de todas las culturas tienen el mismo acceso a él. Sin embargo, existe una graduación en su captación. De este modo tenemos que el conocimiento de los primeros principios es absolutamente universal y no cabe error en su comprensión.

Con relación a los segundos principios tenemos que las conclusiones próximas son, como ya hemos expuesto más arriba, fácilmente captables ya que se basan en una deducción evidente al alcance de todos los hombres. No obstante, y a pesar de la sencillez del raciocinio en la aprehensión de las obligaciones éticas de estas conclusiones próximas, se pueden dar situaciones en las que se dificulte la asunción de estos preceptos. Tal dificultad suele residir en la cultura en la que el sujeto que debe entender los preceptos de los segundos principios se haya educado. Aunque pueden confluir otras causas más personales tales como las pasiones o ciertas tendencias desviadas en el comportamiento.

Si esto es así con las conclusiones próximas, más radicalizado lo tenemos con las remotas pues son en éstas donde más complicado es percibir la universalidad de las obligaciones morales de la ley natural. La cognoscibilidad de tales obligaciones resulta ardua y compleja y no todos los hombres son capaces de aprehenderlas. Obviamente también aquí la cultura, las pasiones, las inclinaciones desviadas de la naturaleza, etc., juegan un papel decisivo que desdibuja la universalidad de los postulados éticos de la ley natural. ${ }^{29}$

La tercera de sus propiedades es la inmutabilidad, es decir, permanece inalterada ya que su fundamento es la esencia de la naturaleza humana que no

29 Cf. Ib., I-II, q.94, 4. Hemos expuesto la gradualidad que se da en el conocimiento de la ley natural. La diferencia, a este respecto, entre los primeros principios y los segundos es que aquéllos son tan evidentes y obvios a la razón humana que su comprensión se hace de un modo inmediato y cierto mientras que éstos requieren de un mayor ejercicio de la razón. Precisamente por esto los moralistas suelen introducir en estos últimos la ignorancia invencible que vendría a actuar como atenuante moral. Dicha ignorancia invencible no se da en los primeros principios, aunque sí en los segundos, ignorancia que solo puede ser transitoria en relación con los preceptos de las conclusiones próximas, y otra de tipo más prolongado y, a veces hasta de por vida si se tratara de personas rudas, en las remotas. 
cambia. No obstante, hay que hacer aquí algunas matizaciones. En cuanto a los primeros principios permanece invariable, no cabe la más mínima mutación. Sin embargo, con respecto a los segundos principios, el Doctor Angélico hace una distinción entre crecimiento por adición y crecimiento por substracción. Para nuestro dominico la ley natural puede mutar por adición, en la medida en que se pueden sacar nuevas deducciones implícitamente contenidas en ella, con el objetivo de que pueda ser mejor entendida y aceptada por todos. Tal es el caso cuando la ley positiva complementa la ley natural. Ésta no puede ser anulada o modificada esencialmente por aquélla ni tampoco puede determinar o establecer algo contrario, pero sí puede explicitarla. Por ejemplo, la ley natural establece que un contrato verbal entre dos personas llevado a cabo desde la libertad es totalmente válido, sin embargo, la ley positiva puede establecer que para la validez de determinados contratos se requiera indispensablemente la firma de las partes. Aquí vemos una adición en la ley natural pero sin alteración de su esencia. ${ }^{30}$

A tenor de este ejemplo podemos ver cómo la ley natural "aumenta", pero sin añadírsele nada nuevo que no estuviera ya implícito de un modo virtual.

Con respecto al cambio por substracción, la argumentación resulta un poco más compleja. Santo Tomás niega, en principio, un cambio en la ley natural por este modo, es decir, como si lo que antes era ley natural ahora dejara de serlo. Lo que él acepta es la posibilidad de cambio en un caso particular de modo ocasional debido a la concurrencia de determinadas circunstancias que, de alguna manera, impidan observar algunos preceptos. ${ }^{31}$ Se trataría de una mutación per accidens, nunca esencial o formal sino simplemente material. Esto significa que pueden darse ciertas circunstancias que cambien el valor moral, pero manteniéndose tanto sus preceptos y su obligatoriedad en cuanto a su contenido. Simplemente no se aplica al caso concreto por haberse producido un cambio en la materia moral.

La cuarta y última propiedad de la que nos tenemos que ocupar es la indelebilidad. Santo Tomás de Aquino hace suya la idea de San Agustín que afirma que la ley natural se encuentra escrita en los corazones de los hombres y no puede ser borrada. Pero aquí hay que volver a traer a colación la distinción entre los primeros principios y los segundos. Aquéllos son indelebles, permanecen siempre en el ser humano de un modo general por lo que no pueden ser borrados. Pero conforme vamos de lo general a lo particular empieza a desdibujarse esta ley de los corazones de los hombres. Por eso, los segundos principios, tanto las

30 Esta mutabilidad de la ley natural por adición no altera su esencia y precisamente por eso nos podemos encontrar aquí con una distinción, en cuanto a la responsabilidad se refiere, entre la moral y el derecho. En el ámbito de la moral, el incumplimiento voluntario e injustificado de un contrato verbal de una de las partes hace que dicha parte incurra en un pecado al no respetar la palabra dada. En el ámbito del derecho el incumplimiento de un acuerdo verbal en aquellos contratos donde la ley exija la firma de ambas partes se exime de responsabilidad a la parte no cumplidora.

31 Cf. Santo TOMÁS de AQUINO, Summa Theologiae, I-II, q. 94, 5. 
conclusiones próximas como las remotas, pueden borrarse por determinadas causas, tales como las malas persuasiones, las costumbres perversas, los malos hábitos contraídos o los vicios contrarios a la naturaleza. ${ }^{32}$

\subsection{La noción de ley natural en la modernidad}

La construcción teórica que Santo Tomás de Aquino hizo de la ley natural no fue aceptada por todos los autores inmediatamente posteriores a él. Algunos de los escolásticos que más la cuestionaron fueron los franciscanos Duns Escoto y Guillermo de Ockham que, por un lado, subrayaban el valor de la voluntad en la configuración de órdenes morales y por otro, negaban el valor ético de la naturaleza, rechazando así la visión tomista de la ley natural. Para ellos, lo bueno o lo malo no depende de instancias objetivas, sino de la voluntad directa del legislador. Si para el Doctor Angélico el decálogo, que pertenece a las conclusiones próximas de los segundos principios como ya vimos, tienen una valoración moral objetiva por basarse en la razón divina que los promulgó, para nuestros franciscanos su valoración moral es puramente subjetiva ya que dependen de la voluntad del Creador. Si matar, robar, adulterar o codiciar está mal es porque Dios como legislador supremo lo decidió así, de tal manera que el que mate, robe, adultere o codicie comete pecado. Pero Dios, desde su libertad, pudo haber decidido justo lo contrario, es decir, que las acciones anteriormente descritas sean buenas en el orden moral por lo que un hombre que realizara dichas acciones estaría encaminándose hacia su propia santificación. ${ }^{33}$

Algo parecido ocurre con la concepción de la naturaleza. Para Santo Tomás de Aquino ésta era algo dado al hombre por el Creador por lo que había que respetar su esencia. De hecho, uno de los motivos por los cuales la ley natural se llama así es precisamente porque los principios éticos derivan de ella. En cambio, para un sector importante del nominalismo, y sobre todo para Duns Escoto, la natura no es un criterio ético de actuación, sino que tiene que ser dominada por el hombre por medio de la técnica. ${ }^{34}$

32 Cf. Ib., I-II, q. 94, 6.

33 Aunque los dos autores citados comparten este planteamiento del voluntarismo propio del nominalismo, sin embargo, se dan en ellos una discrepancia con respecto a la aplicación de dicho voluntarismo a cada uno de los mandamientos. Efectivamente, estos se clasifican en dos tablas. La primera tabla del decálogo está compuesta por tres mandamientos y regula la relación del hombre con respecto a Dios. En cambio, la segunda tabla, compuesta por los siete mandamientos restantes, regula la relación del hombre con su prójimo. Pues bien, Duns Escoto aplica el voluntarismo moral solo a los mandamientos de la segunda tabla mientras que para Ockham, tal voluntarismo cabría aplicarlo también a los mandamientos de la primera.

34 "Scoto no contempla una naturaleza que envuelve al hombre y que le da criterios básicos para sus actuaciones tan plurales como diversas. Él mantiene la visión que los occidentales siempre han tenido (con la excepción de Aristóteles) sobre lo'natural', que es lo que 'está ahí'ya dado. Al no ser creación humana, carece de valor ético para el hombre. Su único destino es ser dominada por el ser humano mediante la técnica”: CARPINTERO, “Desarrollo histórico de la idea de ley natural (II): La Edad Moderna", 76. 
De esta manera se fue configurando el voluntarismo ético que sirvió para ir vaciando a la ley natural de su carácter objetivo y racional. Esta teorización fue asumida por los autores nominalistas de épocas posteriores. Autores, por otra parte, bastante leídos, incluso más que los artífices de esta teorización, entre otras cosas porque los textos de Duns Escoto eran de complicada lectura, de hecho se le conocía como el Doctor Sutil por la excesiva precisión con la que le gustaba exponer sus ideas. Y en cuanto a Guillermo de Ockham, su enfrentamiento abierto con el Papa hizo que la lectura de sus obras no estuviera bien vista. Esto fue lo que llevó a que se prefiriera la lectura de otros autores como Juan de Gerson, Conrado de Summenhart, Gabriel Biel, Jacobo Almain o John Mair, entre otros. ${ }^{35}$

Indudablemente, esta concepción de ley ha traído consigo consecuencias muy concretas en el ámbito político. La más fundamental de ellas es que el voluntarismo ha servido de base teórica para el positivismo jurídico que prima la autoridad sobre la razón: Auctoritas, non veritas, facit legem. ${ }^{36}$ Con esto se consagra la voluntad del legislador por encima de la verdad, consecuencia de la absolutización de la libertad frente a la objetividad del orden moral racional.

Pero frente a este voluntarismo se produjo en la modernidad una fuerte reacción por parte del racionalismo. Si aquel basaba la fundamentación del derecho en la voluntad, este hará lo propio en la razón. Este intento sirvió para que, a la postre, se produjera la secularización del derecho.

Dos fenómenos podemos encontrar en el basamento de este planteamiento. El primero de ellos fue la separación entre fe y razón, algo incoado a finales del Medioevo y que adquirió una mayor fuerza durante la Edad Moderna. Y el segundo fue debido a los innumerables y cruentos enfrentamientos de tipo religioso que se dieron en Europa a partir de la Reforma. Precisamente esto último fue lo que motivó el intento de presentar una noción de ley natural que estuviera desvinculada de cualquier tipo de revelación particular. A partir de ahora, la ley natural empieza a ser presentada por sí misma, como un orden normativo coherente por su esencial racionalidad. Incluso paulatinamente la idea misma de Dios se va retirando de ella, de tal manera que se comenzó a fraguar la idea de que los preceptos morales del orden ético presente en la ley natural mantendrían su fuerza obligatoria aunque Dios no existiera.

El racionalismo surgido como oposición al voluntarismo sirvió para materializar la secularización del derecho. Este hecho influyó incluso en la propia Teología Moral como disciplina la cual, para justificar sus conclusiones, se basaba mucho más en la razón que en la Revelación. De hecho, el uso que se hacía de la Sagrada Escritura era puramente secundario, empleado solo a modo de justificación de los postulados éticos presentados, lo que se conoce como dicta probanda.

35 Cf. Ib., 81.

36 Thomas HOBBES, Leviathan, Parte II, c.26. 
Este modo de presentar a la ley natural, debida a la secularización del derecho, característica de la Edad Moderna ha llegado, en el ámbito teológico, prácticamente hasta las puertas del Concilio Vaticano II. Por eso la Iglesia ha ido trabajando en recuperar la noción de ley natural conectándola con la Revelación $\mathrm{y}$, por consiguiente, con la idea misma de Dios, que es el garante último de la obligatoriedad del orden moral.

\section{UNA NUEVA VISIÓN DE LA LEY NATURAL}

La fuerte secularización jurídica experimentada durante toda la Edad Moderna llegó incluso a sustraer del Magisterio eclesiástico la interpretación de la ley natural. Efectivamente, la concepción racionalista la había concebido como un ente estático e inmutable, interpretable solo desde los postulados de la razón. Por eso quien tuviera un mejor manejo de la lógica deductiva sería quien en mejores condiciones se encontraría para su interpretación. Pero, que todos los hombres tengan acceso a los principios éticos emanados de la ley natural por medio de la razón, ¿debe significar que la Iglesia no pueda presentarse como su instancia interpretativa? Al haberse desvinculado la ley natural, por el proceso secularizador, de la Revelación, no faltaron voces que argüían que la Iglesia debía encargarse de interpretar el dato revelado pero no los principios éticos que se puedan derivar de la ley natural.

Ha sido, precisamente esta mentalidad la que ha llevado a la Iglesia a reivindicar para sí su autoridad para interpretar los principios éticos de la ley natural. Esto es de vital importancia, pues recordemos que, aunque sus postulados morales son aprehensibles por la razón, no todos lo son con el mismo grado de evidencia. Cuanto más nos alejemos de los primeros principios menor claridad de comprensión tendremos, de ahí la importancia de una correcta interpretación.

Por ejemplo, la anticoncepción es contraria a la ley natural, sin embargo, este contenido moral no resulta evidente para muchas personas, motivo por el cual se requiere de una interpretación que se ajuste a la verdad objetiva que siempre coincide con la Revelación, puesto que el autor de una y otra es el mismo: Dios.Y en Él no cabe ni el error ni la contradicción. A este respecto la Iglesia es la única autorizada para la interpretación de ambas.

Este ejemplo que hemos puesto no es solo teórico, sino que ha constituido el contexto teológico que sirvió al Papa Pablo VI para reclamar para sí, como sucesor de Pedro, la autoridad interpretativa en la materia expuesta. Escuchémoslo a él:

“Estas cuestiones exigían del Magisterio de la Iglesia una nueva y profunda reflexión acerca de los principios de la doctrina moral del matrimonio, doctrina fundada sobre la ley natural, iluminada y enriquecida por la revelación divina.

Ningún fiel querrá negar que corresponda al Magisterio de la Iglesia el interpretar también la ley moral natural. Es, en efecto, incontrovertible —como 
tantas veces han declarado nuestros predecesores- que Jesucristo, al comunicar a Pedro y a los apóstoles su autoridad divina y al enviarlos a enseñar a todas las gentes sus mandamientos, los constituía en custodios e intérpretes auténticos de toda ley moral, es decir, no solo de la ley evangélica, sino también de la natural expresión de la voluntad de Dios, cuyo cumplimiento fiel es igualmente necesario para salvarse. En conformidad con esta su misión la Iglesia dio siempre, y con más amplitud en los tiempos recientes, una doctrina coherente tanto sobre la naturaleza del matrimonio como sobre el recto uso de los derechos conyugales y sobre las obligaciones de los esposos." ${ }^{37}$

Como se puede comprobar por el texto apenas citado, el Papa apela a la autoridad conferida por Cristo para poder interpretar la ley natural. Que PabloVI tenga que apelar a su facultad interpretativa exclusiva como obispo de Roma se debió a que en el cristianismo del siglo $X X$ se estaban dando distintas corrientes o posturas sobre cuestiones de moral conyugal. Cada una de estas interpretaciones se hacía desde la luz natural de la razón y, sin embargo, sus diferencias eran notables, sin obviar que muchas de ellas eran claramente contrarias al dato revelado. No solo eso, sino que incluso después del pronunciamiento del Magisterio por medio de la Encíclica citada no faltaron grupos y colectivos católicos que se opusieron a la interpretación oficial realizada por el Pontífice. No obstante, la Iglesia ha sido fiel a su misión de enseñar la verdad doctrinal del Evangelio, también su verdad moral, y para ello ha continuado apelando a la noción de ley natural, sobre todo en las últimas décadas, donde se ha ido acentuando paulatinamente el relativismo ético debido a determinados factores culturales y sociales.

Ha sido precisamente en este contexto donde más necesario se ha visto el presentar la noción de ley natural como basamento para llegar a un consenso sobre el comportamiento moral de las personas en una sociedad cada vez más heterogénea y plural. Este ha sido el motivo por el que la Iglesia encargó a la Comisión Teológica Internacional la confección de un documento que tratase esta cuestión. Dicha comisión asumió el encargo en el mes de octubre del año 2004 y tras más de cuatro años de ardua labor se aprobó finalmente el texto definitivo en el mes de diciembre de 2008 con el título de En busca de una ética universal: un nuevo modo de ver la ley natural. El documento se redactó originariamente en lengua francesa pero fue publicado en italiano en el mes de junio de 2009. Su cometido fundamental es, como ya hemos apuntado, establecer una base que permita diferenciar entre el bien y el mal y llegar así a una conciencia de solidaridad global que posibilite la asunción de unos valores éticos comunes.

De hecho, el documento habla de la necesidad de volver a presentar la noción de ley natural como garante de un mínimo ético exigible socialmente a tenor de cuatro factores sociales. El primero de ellos es debido a que desde

37 PABLO VI, Carta Encíclica sobre la transmisión de la vida humana, Humanae Vitae (25-julio-1968), nº 4, AAS 60 (1968) 483. 
la Ilustración, pero sobre todo a partir del último siglo, la razón ha estado monopolizada por las ciencias empíricas destacando su ausencia en al ámbito de la moral, que ha decaído en un relativismo. Por eso, ante este hecho, se insiste en la necesidad de presentar la noción de ley natural, ya que con ella se alude a la idea de que es el ser humano desde su racionalidad el que va deduciendo el contenido ético inscrito en la misma naturaleza del hombre. Se trataría de fundamentar en la razón las exigencias y obligaciones morales.

Como segundo factor está el individualismo característico de la cultura postmoderna, el cual plantea que es cada sujeto quien va creando sus propios valores. Como estos individuos tienen que vivir en sociedad, entonces ésta viene concebida como un mero contrato donde los sujetos implicados son los que deciden qué valores serán los que configuren su vida en común. En este sentido los valores no dependerían de ninguna instancia objetiva. Pues bien, frente a esta mentalidad, se ve necesario presentar nuevamente la noción de ley natural, ya que con ella se acentúa la idea de que los valores no son consensuados sino descubiertos, es decir, existe una instancia objetiva que garantiza el orden moral.

El tercer factor tiene que ver con el laicismo exacerbado imperante en occidente en nombre del cual se quiere apartar a los creyentes, en especial a los cristianos, del campo del debate público. Algo realmente grave porque hay cuestiones candentes como el aborto, la eutanasia, la experimentación con embriones humanos, etc., donde la Iglesia debe hacer resonar también su voz. Pero desde el laicismo agresivo característico de nuestra cultura se plantea, como estrategia política, dejar fuera de este debate a las confesiones religiosas arguyendo que sus posicionamientos son fundamentalistas y que obedecen a coordenadas culturales obsoletas. Frente a esto es importante que la Iglesia recurra a la ley natural en sus argumentaciones en relación con temas como los anteriormente citados, incidiendo en que es desde la razón desde donde se puede llegar a comprender la postura ética que propone, ya que reflexionar sobre ellos apelando solo a la Revelación provocaría el rechazo de aquellos que no comulgan con la fe católica.

Finalmente, el cuarto factor señalado por el documento de la Comisión Teológica Internacional tiene que ver con una de las amenazas que se esconden detrás del positivismo jurídico, que es el abuso de poder de los diversos gobiernos, que por medio de la promulgación de normas establecen qué es lo que los ciudadanos tienen que hacer y lo que no. Pero frente a esto, la Iglesia recurre a la noción de ley natural para recordar que si una ley promulgada por un gobierno, por muy legítimo que sea, contradice un precepto de la ley natural no debe ser obedecida. De este modo, se valora positivamente la llamada objeción de conciencia $^{38}$, a la que se apela no para desobedecer una ley, sino más bien para obedecer otra de rango superior. ${ }^{39}$

38 Cf. José LÓPEZ GUZMÁN, ¿Qué es la objeción de conciencia?, EUNSA, Pamplona, 2011.

39 Cf. COMISIÓN TEOLÓGICA INTERNACIONAL, En busca de una ética universal: un nuevo modelo de ver la ley natural, $\mathrm{n}^{\circ} 35$. 
Como hemos visto, hay razones de peso para que el Magisterio eclesiástico trabaje por recuperar la noción de ley natural. Sin embargo, creemos que en esta recuperación hay que superar el modelo racionalista, para quien los preceptos morales no son más que una realidad inmutable y a-histórica, pero perfectamente cognoscibles por la razón. Este modelo se ha caracterizado por considerar a la ley natural como un ente estático sin tener en cuenta la historicidad humana. ${ }^{40}$ Es cierto que los preceptos de la ley natural son inmutables, tal y como vimos anteriormente, pero dicha inmutabilidad lo es en relación con los primeros principios. Con respecto a los segundos principios existe la posibilidad de una cierta mutabilidad al aproximarnos a los casos concretos y sus circunstancias. Los autores del modelo racionalista no han tenido esto muy presente, por eso han presentado una visión de ley natural excesivamente estática, ignorando que el hombre es un sujeto histórico. Pero la condición historicista del hombre no debe llevarnos al polo opuesto, es decir, a una visión circunstancialista de la ética, donde todo dependa del prisma de la cultura y de las situaciones concretas en las que actuemos. Por ello juzgamos oportuno que la presentación de la noción de ley natural que debe hacerse en la sociedad actual es aquella que sepa integrar la inmutabilidad de sus primeros principios con el devenir de visiones éticas como resultado de las sucesiones de culturas.

Por ejemplo, retomando el caso del enterramiento de Polinices por parte de su hermana Antígona, vimos como ésta apelaba a una ley proveniente de los dioses cuando fue interrogada por su tío Creonte. Con esto podemos afirmar que el respeto a los cadáveres humanos es de ley natural, pero el cómo materializa cada cultura dicho respeto es algo que puede variar. En el caso particular de la Grecia Antigua este respeto consistía en el enterramiento, pero es posible que en otra cultura dicho respeto se llevara a cabo por medio de la cremación. En este sentido habría que decir que la ley natural posee un cierto grado

40 El documento de la Comisión Teológica Internacional ya advierte sobre esta cuestión cuando afirma que "El modelo racionalista moderno de la ley natural se caracteriza por: 1) creencia esencialista en una naturaleza humana inmutable y a-histórica, respecto a la cual la razón puede perfectamente captar la definición y las propiedades esenciales; 2) se pone entre paréntesis la situación concreta de las personas humanas y la historia de la salvación, marcada por el pecado y la gracia, cuya influencia sobre el conocimiento y la práctica de la ley natural son, sin embargo, determinantes; 3) la idea de que es posible que la razón deduzca a priori los preceptos de la ley natural a partir de la definición de la esencia del hombre; 4) la extensión máxima de los preceptos deducidos así, de modo que la ley natural aparece como un código de leyes completas que regula casi todos los comportamientos. Esta tendencia a extender el campo de las determinaciones de la ley natural ha sido el origen de una grave crisis, en particular debido a que con el desarrollo de las ciencias humanas, el pensamiento occidental ha tomado conciencia de la historicidad de las instituciones humanas y del carácter relativo y cultural de muchos comportamientos que se justificaban con frecuencia recurriendo a la ley natural. Este desfase entre la teoría abstracta maximalista y la complejidad de los datos empíricos explica en parte la desafección respecto a la idea misma de ley natural. Para que la noción de ley natural pueda servir para elaborar una noción de ética universal en una sociedad secularizada y pluralista como la nuestra hay que evitar presentarla en la forma rígida que ha adquirido en particular en el contexto del racionalismo moderno": $I b ., \mathrm{n}^{\circ} 33$. 
de indeterminación que el derecho positivo habrá de concretar a situaciones particulares. $^{41}$

\section{A MODO DE CONCLUSIÓN}

Hemos visto cómo la noción misma de ley natural tiene un origen pre-cristiano. La idea de que existe una ley más allá de la meramente consensuada por los miembros de una sociedad ha estado presente en todas las culturas.Y es que allí donde hay un sujeto racional se da la posibilidad de la percepción de la existencia de un orden moral que impone prohibiciones y establece obligaciones.

En nuestras sociedades occidentales, tan caracterizadas por el multiculturalismo generado por los distintos movimientos migratorios y por el galopante proceso globalizador, se hace cada vez más necesario construir una ética común con preceptos valederos para los diversos grupos y etnias que las componen. Cada grupo cultural aparece en este escenario pluralista con su propio sistema axiológico, en el que en no pocas ocasiones los valores que la integran entran en confrontación con los de otros sistemas con los que tiene que convivir. No se trata de ver qué conjunto de valores es el que debe imponerse sobre los otros, ya que si así fuera la convivencia no sería pacífica. Es por ello por lo que recuperar la noción de ley natural se hace cada vez más vital ya que nos permitiría poder construir esa ética común.

En este sentido habría que recurrir, no a la cultura que ha fraguado el conjunto axiológico de un determinado grupo, sino a la razón que es capaz de aprehender, partiendo de la naturaleza humana, los principios rectores del comportamiento cívico, asumiendo entre todos un orden moral no específico pero sí genérico y comunitario. La Iglesia, conocedora de esta realidad, ha entendido que para hacerse oír en una sociedad cada vez más descristianizada, secularizada y heterogénea como la occidental, debe apelar a la ley natural, o dicho con otras palabras, las propuestas morales de la Iglesia deben ser comprensibles racionalmente por nuestros contemporáneos. Basar tales propuestas solo en la Tradición cristiana o en la Biblia sería un error de bulto, no porque en estas dos instancias no se encuentre la verdad, sino porque son muchas las personas que no fundamentan sus principios éticos en la revelación cristiana. Que las relaciones sexuales fuera del matrimonio, el adulterio, el divorcio o las prácticas homosexuales constituyen un desorden moral es algo que tiene una sólida fundamentación tanto en la Escritura como en la Tradición de la Iglesia, pero con exponer su ilicitud moral amparándonos exclusivamente en el dato revelado solo conseguiremos que tal valoración ética sea rechazada por aquellos que no

${ }^{41}$ Acerca de la indeterminación de la ley natural y de su posterior concreción por parte del derecho positivo cf. Sebastián CONTRERAS, "La ley natural y su falta de determinación, apuntes sobre la teoría clásica de la determinación del derecho natural”, Boletín Mexicano de Derecho Comparado 47 (2014) 839-866. 
comulguen con el credo católico e incluso por aquellos otros que aun siendo católicos consideren que dicha valoración moral pertenece a unas coordenadas histórico-culturales distintas.

Así pues, consideramos que tanto el Magisterio como la Teología Moral deben, sin obviar ni contradecir la revelación, realizar el esfuerzo de presentar racionalmente el mensaje moral a los hombres de hoy para que pueda ser aprehendido por todos aquellos que busquen la verdad ética con independencia de cuál sea su credo o su ideología. 